\title{
HLA-DQA1*04:01 is related to a higher multiple sclerosis lesion load on T2/Flair MRI sequences
}

\author{
O HLA-DQA 1*04:01 está relacionado com uma alta carga lesional na ressonância \\ magnética em T2/Flair nos pacientes com esclerose múltipla
}

\author{
Fabio NORO', Soniza Vieira ALVES-LEON², Fabricia Lima FONTES-DANTAS², Paulo Roberto VALLE BAHIA?', \\ Rodrigo Ferrone ANDREIUOLO3, Fernanda Cristina RUEDA LOPES', Valeria Coelho Santa Rita PEREIRA², \\ Livia de Almeida Afonso ABI-HAILA², Renan Amaral COUTINHO², Amanda Dutra de ARAUJO², Edson MARCHIORI ${ }^{1}$
}

\begin{abstract}
Background: The genetic predisposition to multiple sclerosis (MS) is associated with HLA alleles, especially HLA-DRB1*15:01. Objective: To identify associations between findings in magnetic resonance imaging (MRI) and genetic features in a Brazilian cohort of patients with MS. Methods: We retrospectively studied data from 95 consecutive patients with MS. Two independent observers who were blinded to the clinical data identified black holes and enhanced lesions on T1 MRI sequences, and counted and measured contrast-enhanced lesions on T2 and Flair (fluid attenuation inversion recovery) sequences. Cases were classified according to lesion size, number, and volume. The HLA-DRB1, HLA-DQB1, and HLA-DQA1 alleles, and the rs4774, rs3087456, rs6897932, rs731236, and rs1033182 single nucleotide polymorphisms were identified by polymerase chain reaction amplification with sequence-specific primers using the One Lambda Inc. Kit, Canoga Park, CA, USA. Results: Patients with the HLA-DQA1*04:01 allele had lesion load (adjusted for age, sex, and MS duration) above median compared with patients with other HLA-DQA1 alleles $(p=0.02)$. There were no differences among all the other HLA alleles and single nucleotide polymorphisms and lesion load. Conclusions: The correlation of the HLA-DQA1*04:01 allele with a higher lesion load on T2/Flair MRI sequences suggests that the presence of this allele is associated with the risk of greater MS severity.
\end{abstract}

Keywords: Multiple Sclerosis; HLA-DQ Antigens; HLA-DRB1 Chains; Genotype; Magnetic Resonance Imaging.

\section{RESUMO}

Antecedentes: A predisposição genética para a esclerose múltipla (EM) está associada a alelos HLA, principalmente o HLA-DRB1*15:01. Objetivo: Identificar associações entre lesões na ressonância magnética e características genéticas em uma coorte brasileira de pacientes com EM. Métodos: Estudamos retrospectivamente os dados de 95 pacientes consecutivos com EM. Dois observadores independentes que desconheciam os dados clínicos identificaram "black holes" e lesões realçadas pelo contraste nas sequências de ressonância magnética T1 e contaram e mediram as lesões nas sequências T2 e FLAIR (fluid attenuated inversion recovery). Os casos foram classificados de acordo com tamanho, número e volume da lesão. Os alelos HLA-DRB1, HLA-DQB1 e HLA-DQA1 e os polimorfismos de nucleotídeo único rs4774, rs3087456, rs6897932, rs731236 e rs1033182 foram identificados por amplificação de reação em cadeia da polimerase com iniciadores específicos de sequência usando o kit One Lambda Inc., Canoga Park, CA, EUA. Resultados: Os pacientes com alelo HLA-DQA1*04:01 apresentaram carga de lesão (ajustada para idade, sexo e duração da EM) acima da mediana em comparação com outros pacientes com demais alelos HLA-DQA1 ( $p=0,02)$. Não houve diferenças entre todos os outros alelos HLA e polimorfismos de nucleotídeo único e carga lesional. Conclusões: A correlação do alelo HLA-DQA1*04:01 com maior carga de lesão nas sequências de RM em T2 sugere que a presença desse alelo pode estar associada ao risco de maior gravidade da EM.

Palavras-chave: Esclerose Múltipla; Antígenos HLA-DQ; Cadeias HLA-DRB1; Genótipo; Imageamento por Ressonância Magnética.

\footnotetext{
'Universidade Federal do Rio de Janeiro, Departamento de Radiologia, Rio de Janeiro RJ, Brazil.

¿Universidade Federal do Rio de Janeiro, Departamento de Radiologia, Rio de Janeiro RJ, Brazil.

${ }^{3}$ Rede Dor-São Luiz, Rio de Janeiro RJ, Brazil.

FN (D) https://orcid.org/0000-0002-5193-5434; SVAL (D) https://orcid.org/0000-0002-1538-6730; FLFD (D) https://orcid.org/0000-0002-5201-0927; PRVB (D) https://orcid.org/0000-0002-4765-8526; RFA (D) https://orcid.org/0000-0001-5768-6611; FCRL (D) https://orcid.org/0000-0002-3782-8624; VCSRP (D) https://orcid.org/0000-0002-7212-5043; LAAA (D) https://orcid.org/0000-0002-2515-1855; RAC (D) https://orcid.org/0000-0002-9924-5053; ADA (D) https://orcid.org/0000-0001-6233-1428; EM (D) https://orcid.org/0000-0001-8797-7380

Correspondence: Fabio Noro; Email: fncursos@gmail.com.

Conflict of interest: There is no conflict of interest to declare.

Authors' contributions: FN: conceptualization, methodology, validation, formal analysis, investigation, writing of original draft, project administration; SVAL: conceptualization, methodology, writing (review and editing); FLFD: validation, writing (review and editing); PRVB: conceptualization, methodology; RFA, FCRL, VCSRP, LAAAH, RAC, ADA: investigation; EM: writing (review and editing), formal analysis.

Received on October 15, 2020; Received in its final form on December 02, 2020; Accepted on December 23, 2020.
} 


\section{INTRODUCTION}

The most important confirmed genetic factor for susceptibility to multiple sclerosis (MS) has been identified in the human leukocyte antigen (HLA) class II region on the short arm of chromosome 6. The HLA-DRB1*15:01 allele is strongly associated with MS, especially in Caucasian populations ${ }^{1,2,3,4,5,6}$. Associations between HLA genotypes and age at MS onset are probably related to the HLA-DQB1*06:02, HLADRB1*15:01, HLA-DQA1*01:01, and HLA-DRB1*01:01 haplotypes $^{1,2,7}$. The presence of the HLA-DR2 haplotype (molecular designations HLA-DRB1*15:01, HLA-DQA1*01:02, and HLA-DQB1*06:02) was associated with an increased risk of clinically definite MS development within five years in 178 patients with optic neuritis 8 .

Recently, the International Multiple Sclerosis Consortium published a large metanalysis demonstrating the importance of HLA-DRB1*15:01, HLA-DQA1, and HLA-DQB1 interaction and its role in peripheral immune cells and microglia susceptibilities in MS patients9.

Baranzini et al. ${ }^{10}$ found 242 single nucleotide polymorphisms (SNPs) related to MS susceptibility, including 65 SNPs in the major histocompatibility complex of chromosome 6p21.3. Another work suggests that the polymorphisms CIITA -168AA, CIITA $+1614 \mathrm{GG}$, and CIITA $+1614 \mathrm{GC}$ are associated with a better clinical course of MS in Brazilian patients with the disease ${ }^{11}$.

In this retrospective study, we searched for associations among the HLA-DRB1, HLA-DQA1, and HLA-DQB1 haplotypes and the following SNPs: rs4774 and rs3087456 (CIITA gene), rs6897932 (IL7R gene), rs731236 (VDR gene), and rs1033182 (ESR gene) and MRI features, mainly lesion load (LL), number of black holes (black lesions on T1 MRI) (BH), and enhanced lesions (EL) in a cohort of 95 Brazilian patients with MS.

\section{METHODS}

\section{Patients}

We retrospectively analyzed data from 95 patients (60 women and 35 men) with MS diagnosed on clinical and laboratory bases who were followed as outpatients and during periods of eventual hospitalization during the last 15 years at the Hospital Universitário Clementino Fraga Filho/Universidade Federal do Rio de Janeiro (HUCFF-UFRJ). All subjects met the $2017 \mathrm{McD}$ nold criteria for the diagnosis of $\mathrm{MS}^{12}$. According to disease progression, MS was classified as relapsing-remitting (RR), primarily progressive (PP), and secondarily progressive (SP).

We did not include patients older than 71 years old (at the time of MRI) because of the usual hyperintensities from the natural process of aging that could be interpreted as MS lesion load.

The National Council for Ethics in Research approved this study (no. 1265), and written informed consent was obtained from all participants. A single MRI examination of the skull and whole spine (neuroaxis) was chosen for comparison with the clinical situation at a random moment in MS evolution for each patient. We also recorded disease duration, the interval between MS symptom onset and MRI examination, the clinical situation, and the relationship to genetic characteristics.

Clinical evaluations were performed by the team of neurologists at HUCFF-UFRJ, which was blinded to the MRI findings, using Kurtzke’s Expanded State Disability Scale ${ }^{13}$.

\section{Magnetic resonance imaging evaluation}

MRI examinations were performed in a 1.5- $\mathrm{T}$ scanner (Magneton Avanto; Siemens, Munich, Germany) with a 12-channel head coil using a conventional protocol (Table 1).

The presence, size, and location of hyperintense lesions on T2/Flair (fluid attenuation inversion recovery) sequences were determined. The number of $\mathrm{BH}$ and enhanced lesion (EL) were counted. Following the modified $2017 \mathrm{McD}$ onald criteria, lesion locations were recorded as periventricular, justacortical (subcortical/cortical), posterior fossa, and spinal cord ${ }^{11}$. Two observers with 25 and 10 years of experience who were blinded to patient information counted and measured the lesions visually/manually, without the use of an automatic tool. Any disagreement was resolved by consensus.

After this evaluation, the bright lesions on T2 were classified according to size (0-4.9, 5-9.9, 10-19.9, and $\geq 20 \mathrm{~mm}$ ). Based on size classes, estimated average lesion volumes were assigned with lesions considered to be spherical or ellipsoid ( 0 $-4.9 \mathrm{~mm}=0.01 \mathrm{~mL}, 5-9.9 \mathrm{~mm}=0.27 \mathrm{~mL}, 10-19.9 \mathrm{~mm}=1.76 \mathrm{~mL}$, and $>20 \mathrm{~mm}=4.18 \mathrm{~mL}$ ). Examples of how the lesions were measured are shown in Figures 1 and 2.

The lesion load (LL) was estimated by multiplying the number of lesions by their respective estimated average volumes and summing the results. The LL was also calculated separately according to the McDonald criteria locations. All the LL comparisons among groups were adjusted for age, sex, and illness duration.

The median adjusted lesion load (mLL) was $19.8 \mathrm{~mL}$ (in the whole cohort), and we considered this value as the threshold to compare different genetic features groups.

\section{DNA typing}

DNA was extracted from blood samples collected on filter paper using the organic method and quantified by spectrophotometry at $260 / 280 \mathrm{~nm}$. The alleles HLA-DRB1, HLADQB1, and HLA-DQA1 and SNPsrs4774,rs3087456,rs6897932, rs731236, and rs1033182 were identified by polymerase chain reaction amplification with sequence-specific primers using the One Lambda Inc. Kit (Canoga Park, CA, USA) according to the manufacturer's recommendations. Then, capillary electrophoresis was performed using an ABI PRISM ${ }^{\circledR} 3500$ Genetic Analyzer (Applied Biosystems, Foster City, CA, USA), 
Table 1. Magnetic resonance imaging parameters of patients with multiple sclerosis.

\begin{tabular}{|c|c|c|c|c|c|c|c|}
\hline Sequences & & Matrix & FOV & slice & TR & TE & Flip \\
\hline \multirow{9}{*}{ Brain } & T1 MPR Sag & $256 \times 256$ & 250 & 1 & 1940 & 295 & 15 \\
\hline & $\mathrm{DP}+\mathrm{T} 2 \mathrm{TSE} \mathrm{Ax}$ & $320 \times 126$ & 230 & 4 & 3100 & 7.3 & 150 \\
\hline & T2 Flair Sag & $256 \times 244$ & 230 & 4 & 9000 & 83 & 180 \\
\hline & T1 SE Ax MT & $256 \times 144$ & 230 & 5 & 505 & 9 & 90 \\
\hline & Flair 3D Sag & $256 \times 218$ & 260 & 1 & 5000 & 418 & Empty \\
\hline & Diffusion & $160 \times 160$ & 240 & 5 & 3500 & 83 & Empty \\
\hline & T2 TSE AX & $320 \times 216$ & 220 & 3 & 3700 & 102 & 150 \\
\hline & Epi 2D - DTI & $160 \times 160$ & 240 & 3 & 4000 & 82 & Empty \\
\hline & Swi 3D Ax & $256 \times 177$ & 230 & 2 & 49 & 40 & 15 \\
\hline \multirow{7}{*}{ SPINE } & T1 TSE Sag Cerv & $320 \times 224$ & 220 & 3 & 463 & 9 & 132 \\
\hline & T1 TSE Sag Dors & $512 \times 307$ & 320 & 35 & 645 & 10 & 150 \\
\hline & Stir Sag Cerv & $320 \times 256$ & 250 & 3 & 4170 & 87 & 150 \\
\hline & Stir Sag Dors & $320 \times 224$ & 320 & 3.5 & 5120 & 86 & 150 \\
\hline & T2 Med 2 Ax Dors & $320 \times 24$ & 250 & 4.5 & 602 & 18 & 30 \\
\hline & T2 Med2 Ax Cerv & $320 \times 192$ & 200 & 4 & 606 & 18 & 30 \\
\hline & T2 TSE Sag & $320 \times 224$ & 220 & 3 & 2940 & 81 & 150 \\
\hline
\end{tabular}

FOV: field of view;TR: repetition time;TE: echo time; MPR: multiplanar reconstruction; TSE: turbo spin echo; Flair:fluid attenuated inversion recovery; SE: spin echo; MT: magnetization transference; Epi: echo planar imaging; DTI: diffusion tensor imaging; Swi: susceptibility weighted imaging; Stir: Short tau inversion recovery.

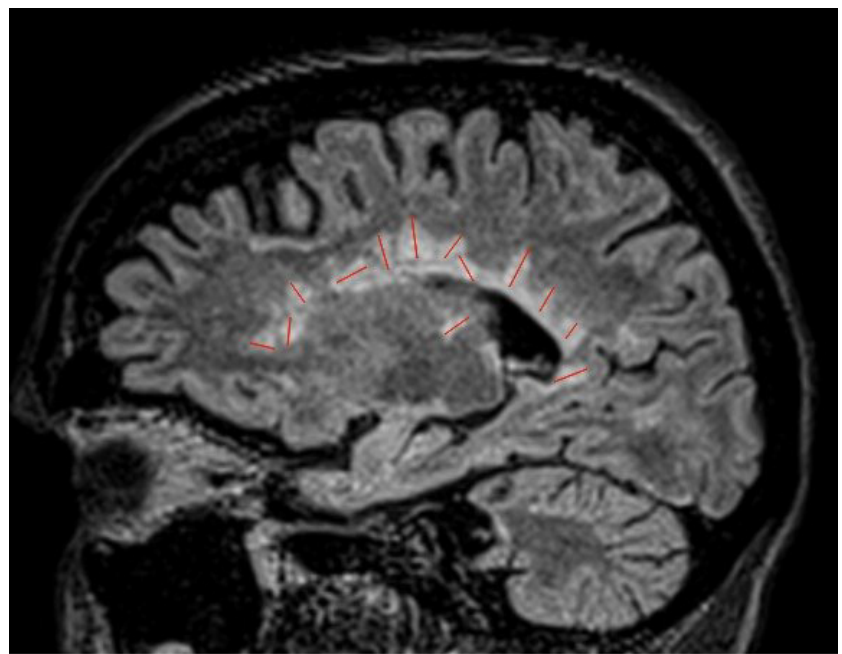

Figure 1. Sagital Flair (fluid attenuation inversion recovery). Example of measurements in a large lesion load case. The largest axis of lesions were measured (lines).

and the results were analyzed with GeneMapper 4.0 software, Thermo Fisher Scientific (Waltham, MA, USA).

\section{Statistical analysis}

Due to the non-normal distribution of LL data within groups, we used the median rather than mean for comparing different genetic features (HLA type and its alleles and SNPs).

Patient information was entered into a Microsoft Excel $^{\circledast}$ (Redmond, WA, USA) database and later exported

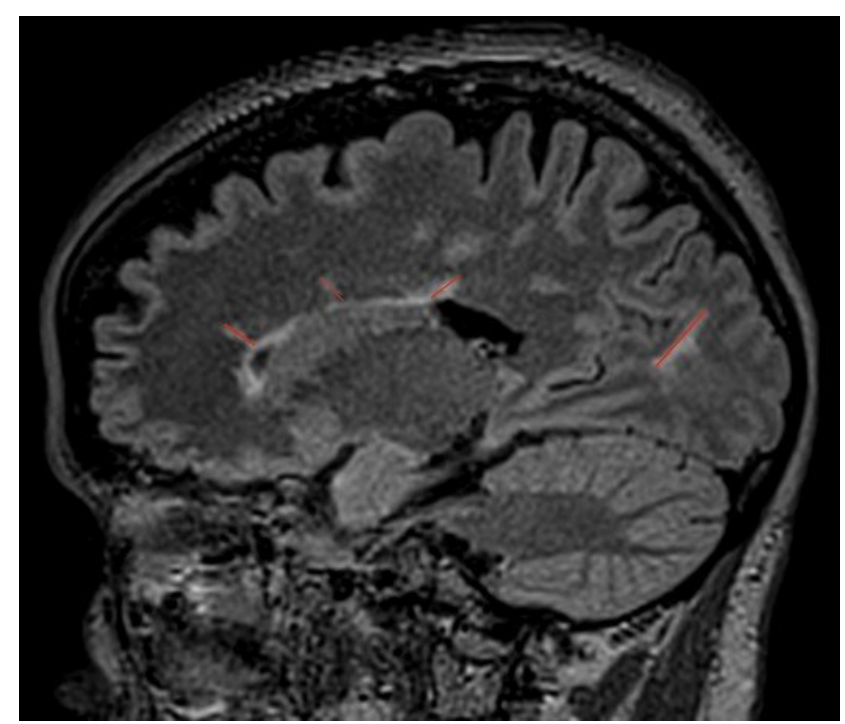

Figure 2. Sagital Flair (fluid attenuation inversion recovery). Example of measurements in a mild lesion load case. The largest axis of lesions were measured (lines).

to the Statistical Package for the Social Sciences (SPSS ver. 14.0, IBM, Armond, NY, USA). Proportional data were compared using the chi-squared test (Fisher or Yates, as needed). Interval and ratio data were submitted to analysis of variance with a comparison of multiple groups according to Tamhane's statistics, as the variance between groups was not homogeneous. P value was considered significant if $<0.05$ 
RESULTS

\section{Associations of demographic and clinical characteristics with clinical multiple sclerosis categories}

Of the 95 patients analyzed, 73 had RR, 9 had PP, and 13 had SP MS. Patient characteristics and timing of MRI examination are shown in Table 2 . The mean age was significantly greater in the $R R$ group than in the PP group $(p=0.02)$. Male sex predominated in the PP group relative to the RR and SP groups (chi-square $=5.3, p=0.01$ ) The mean age at disease onset was significantly greater in the PP group than in the RR group $(p=0.02)$. The average disease duration and age at the time of MRI examination did not differ significantly among groups.

\section{Associations of magnetic resonance imaging}

findings with clinical multiple sclerosis categories

MRI features and parameters are shown according to MS progression type in Table 3. The mean LL in the posterior fossa was significantly greater in the SP group than in the RR group ( $\mathrm{p}<0.05$ ); no significant difference was found in the LL or number of lesions in any other region of the brain. The mean number of BHs was significantly greater in the SP group than in the RR group ( $\mathrm{p}<0.02)$, and the mean number of ELs was significantly greater in the RR group than in the PP group ( $\mathrm{p}<0.04)$.

\section{Associations of lesion load and genetic features}

We compared the mLL with the SNPs rs3087456, rs4774, rs6897932, rs731236, and rs1033182, considering the three possible genetic variations (wild type homozygous, heterozygous, and polymorphic homozygous), and found no significant correlation (Table 4). These SNPs were the only ones available for this study, given the scarcity of resources.

Comparison of the mLL with the HLA genes DQA1, DRB1, and DQB1 and their respective alleles revealed a significant difference only in the HLA-DQA1*04:01 allele. Seventeen of $24(71 \%)$ patients with the HLA-DQA1*04:01 allele had LL values above the median $(19.8 \mathrm{~mL})$, in contrast to those with other alleles [26/64 (41\%), chi-square=5.2, $\mathrm{p}=0.02$; Table 5).

Table 2. Patient characteristics according to clinical multiple sclerosis types.

\begin{tabular}{ccccccc}
\hline$n$ & $\begin{array}{c}\text { Age } \\
( \pm S D)-\text { range }\end{array}$ & Sex $(M / F)$ & $\begin{array}{c}\text { Age at illness onset: } \\
\text { mean }( \pm S D)\end{array}$ & $\begin{array}{c}\text { Mean time of illness } \\
(\text { months }): \text { mean }( \pm S D)\end{array}$ & $\begin{array}{c}\text { Age at MRI moment: } \\
\text { mean }( \pm S D)\end{array}$ & $\begin{array}{c}\text { EDSS: mean } \\
( \pm S D)\end{array}$ \\
\hline RR & 73 & $\begin{array}{c}27.9(10.9) \\
5-56\end{array}$ & $24 / 49$ & $27.9(10.9)$ & $17.1(11.4)$ & $45.1(13.4)$ \\
PP & 9 & $\begin{array}{c}37.6(7.4) \\
27-47\end{array}$ & $7 / 2$ & $37.6(7.4)$ & $15.7(14.8)$ & $54.6(12.8)$ \\
SP & 13 & $\begin{array}{c}31.9(12.9) \\
12-57\end{array}$ & $4 / 9$ & $31.9(12.9)$ & $12(13.7)$ & $5.1(1.6)$ \\
\hline
\end{tabular}

RR: relapsing-remitting; PP: primarily progressive; SP: secondarily progressive; EDSS: Expanded Disability Status Scale.

Table 3. Magnetic resonance imaging features according to clinical multiple sclerosis form.

\begin{tabular}{|c|c|c|c|}
\hline \multirow[b]{2}{*}{ MRI features } & \multicolumn{3}{|c|}{ Clinical types } \\
\hline & $\begin{array}{c}\mathrm{RR} \\
\text { mean }( \pm \mathrm{SD})\end{array}$ & $\begin{array}{c}P P \\
\text { mean }( \pm S D)\end{array}$ & $\begin{array}{c}\mathrm{SP} \\
\text { mean }( \pm \mathrm{SD})\end{array}$ \\
\hline Periventricular (LL) & $12.9(1.5)$ & $16.9(21.9)$ & $32.9(5.5)$ \\
\hline Periventricular (NL) & $38.4(26.5)$ & $31(12.2)$ & $46.2(22.4)$ \\
\hline Justacortical (LL) & $3(3.8)$ & $10(20.7)$ & $16.3(45.8)$ \\
\hline Justacortical (NL) & $26.2(20.3)$ & $27.6(15.2)$ & $31.9(14.3)$ \\
\hline Posterior fossa (LL) & $0.8(1.6)$ & $0.4(0.7)$ & $2.8(3.1)$ \\
\hline Posterior fossa (NL) & $4.3(7.2)$ & $2.6(2.6)$ & $13.5(10.5)$ \\
\hline Spinal cord (LL) & $5.1(9.2)$ & $7.1(11.1)$ & $14.7(13.8)$ \\
\hline Spinal cord (NL) & $6.1(16.9)$ & $2.3(2.8)$ & $6.5(5.8)$ \\
\hline Number of lesions (all CNS) & $75.7(52.9)$ & $63.8(24.2)$ & $97(38.8)$ \\
\hline Load lesion (all CNS) & $21.9(21.8)$ & $34.1(44.1)$ & $66.8(109)$ \\
\hline Load lesion index & $0.3(0.4)$ & $0.5(1.8)$ & $0.7(2.8)$ \\
\hline Number of black holes & $2.7(5.3)$ & $4.8(5.9)$ & $16.3(14.6)$ \\
\hline Number of enhanced lesions & $1.9(5.3)$ & $0.2(0.7)$ & $0.8(1.5)$ \\
\hline
\end{tabular}

RR: relapsing-remitting; PP: primarily progressive; SP: secondarily progressive; LL: lesion load (in ml); NL: number of lesions. 
Table 4. Single nucleotide polymorphism frequencies according to the median total adjusted lesion load (adjusted for age, sex, and multiple sclerosis duration).

\begin{tabular}{|c|c|c|c|c|c|}
\hline SNPs & & $\mathrm{mLL} \geq 19.8 \mathrm{~mL} \mathrm{n} /(\%)$ & $\mathrm{mLL}<19.8 \mathrm{~mL} \mathrm{n} /(\%)$ & Total n/\% & $p$-value \\
\hline \multirow{3}{*}{ rs3087456 } & $\mathrm{AH}$ & $40 / 51$ & $39 / 49$ & $79 / 100$ & \multirow{3}{*}{0.41} \\
\hline & $\mathrm{HZ}$ & $3 / 37$ & $5 / 35$ & $8 / 100$ & \\
\hline & $\mathrm{PH}$ & $5 / 71$ & $2 / 29$ & $7 / 100$ & \\
\hline \multirow{3}{*}{ rs4774 } & $\mathrm{AH}$ & $2 / 33$ & $4 / 67$ & $6 / 100$ & \multirow{3}{*}{0.66} \\
\hline & $\mathrm{HZ}$ & $8 / 53$ & $7 / 47$ & $15 / 100$ & \\
\hline & $\mathrm{PH}$ & $38 / 52$ & $35 / 48$ & 73/100 & \\
\hline \multirow{3}{*}{ rs6897932 } & $\mathrm{AH}$ & $1 / 100$ & $0 / 0$ & $1 / 100$ & \multirow{3}{*}{0.61} \\
\hline & $\mathrm{HZ}$ & $7 / 50$ & $7 / 50$ & $14 / 100$ & \\
\hline & $\mathrm{PH}$ & $40 / 51$ & $39 / 49$ & 79/100 & \\
\hline \multirow{3}{*}{ rs731236 } & $\mathrm{AH}$ & $43 / 51$ & $41 / 49$ & $84 / 100$ & \multirow{3}{*}{0.94} \\
\hline & $H Z$ & $5 / 50$ & $5 / 50$ & $10 / 100$ & \\
\hline & $\mathrm{PH}$ & $48 / 51$ & $46 / 49$ & $94 / 100$ & \\
\hline \multirow{3}{*}{ rs1033182 } & $\mathrm{AH}$ & $1 / 50$ & $1 / 50$ & $2 / 100$ & \multirow{3}{*}{0.75} \\
\hline & $\mathrm{HZ}$ & $4 / 40$ & $6 / 60$ & $10 / 100$ & \\
\hline & $\mathrm{PH}$ & $43 / 52$ & $39 / 48$ & $82 / 100$ & \\
\hline
\end{tabular}

SNP: single nucleotide polymorphism; mLL: median total adjusted lesion load; AH: ancestral homozygous; HZ: heterozygous; PH: polymorphic homozygous.

Table 5. HLA-DQA1 allele frequencies according to the median total adjusted lesion load (adjusted for age, sex, and multiple sclerosis duration).

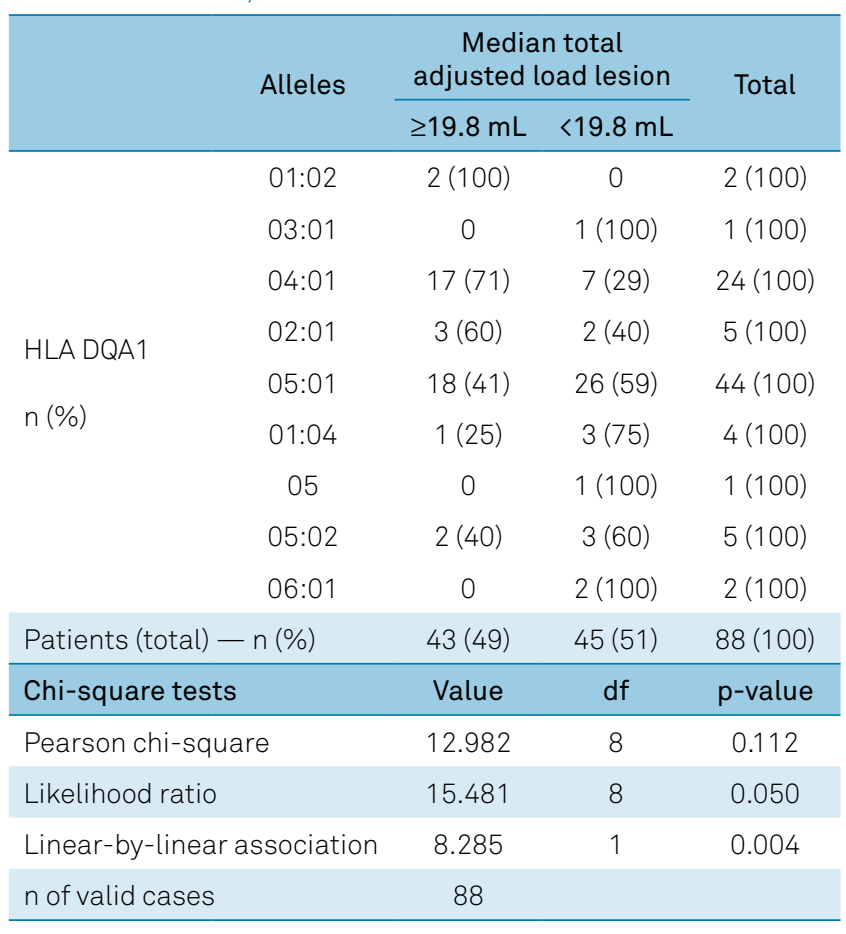

HLA-DQA $1 * 04: 01 \quad(17 / 24=70.8 \%)$ vs. all the other HLA-DQA1 alleles $(26 / 64=40.6 \%$; chi-square $=5.2, p<0.02)$.

Comparison of the mLL with HLA genes DQA1, DRB1, and DQB1 and their respective alleles considering the three clinical MS types (RR, PP, and SP) demonstrated differences between RR and SP patients with HLA-DRB1*03:01 (chisquare $=5.4, \mathrm{p}=0.02$ ), $\mathrm{DRB1}{ }^{* 11}: 02$ (chi-square $=5.4, \mathrm{p}=0.02$ ), and
DQB1 $* 2: 01$ (chi-square=4.9, $\mathrm{p}=0.03$ ). In addition, there was a difference between PP and SP patients with DQB1*05:03 (chi-square $=5.0, \mathrm{p}=0.03$ ). However, this result had no statistical power once the total number of patients was too small (Supplementary Files).

\section{DISCUSSION}

The significance of a high mLL in patients who have the HLA-DQA1*04:01 allele may suggest a possible susceptibility to high disease severity. MRI criteria are widely used for the diagnosis and monitoring of MS, but they are constantly evolving. For example, the 2017 modifications to the MRI criteria changed the dissemination in space concept ${ }^{12}$.

An increasing number of studies have examined genetic associations with the LL, lesion shape, and topological lesion distribution in patients with MS. Gouraud et al. ${ }^{14}$ identified 31 significant genetic variations related to MS lesion topology on MRI. They combined with genetic risk score in MS activity and progression. Kalincik et al. ${ }^{15}$ found similar results in another study. Patients with MS carrying the susceptibility allele HLA-DRB1*15:01 had a greater brain lesion volume than non-carriers?

In Brazilian patients, a population characterized by ethnic admixture, HLA-DRB1*15:01, has been shown to confer MS susceptibility based on clinical features ${ }^{16}$. Additionally, genetic predictors of MS susceptibility, disease activity, and severity have been identified in two other studies of Brazilian patients ${ }^{11,17}$.

In this study, we highlighted the role of the HLA-DQA1 gene in MS susceptibility. We did not find in the literature a 
specific relationship between the allele 04:01 and MS susceptibility or severity.

Reports correlate HLA-DQA1 alleles to several autoimmune diseases besides $\mathrm{MS}^{18,19,20}$. Susceptibility to MS has been associated with the HLA-DRB5*01:01, HLADRB1*15:01, HLA-DQA1*01:02, and HLA-DQB1*06:02 haplotypes, which dominate genetic contributions to MS risk $^{21}$. However, a report about genetic predisposition in Sardinian families failed to identify any shared epitopes in the DR and DQ molecules that segregated with disease susceptibility ${ }^{22}$.

The role of DRB1* and DQA1* molecules in susceptibility to experimental autoimmune encephalomyelitis have been demonstrated ${ }^{23}$. We found no statistical significance between MRI features (LL, number of BH, and EL) and other HLA haplotypes, especially HLA-DRB1, which is most frequently reported in association with MS severity on MRI. However, there are controversial reports in the literature.

In 2003, Zivadinov et al. ${ }^{24}$ reported a significant relationship of HLA-B7 with the LL and number of BHs. In 2007 and 2009, Zivadinov et al. ${ }^{25,26}$ reported correlations of HLA-DRB1*15:01 and HLA-DRB1*12 with a larger number of BHs and smaller cerebral volumes, but not with the LL. In 2009, Okuda et al. ${ }^{27}$ reported a correlation between high LLs and the HLA-DRB1*15:01 allele. Hooper-van Veen et al. ${ }^{28}$ described associations of the CD28, IFNGR2, and IL1B-511 genes with a larger number of BHs, but not with the LL. In contrast, Schreiber et al. ${ }^{29}$ reported that they found no significant correlation between the MS LL and HLA genes.

Recently, Lysandropoulos et al..$^{30}$ reported greater clinical severity and more lesions in patients with HLA-A 2 . However, their results for the HLA-DRB1, HLA-DQB1, and HLA-B*08 alleles were inconclusive. In 2020, Lysandropoulos et al. ${ }^{31}$ confirmed these findings in a slightly larger group of patients, with a longer clinical and imaging follow-up.

We found no relationship between MRI features of MS severity and SNPs, specifically rs3087456, rs4774, rs6897932, rs731236, and rs1033182.
Sombekke et al. ${ }^{32}$ and Baranzini et al. ${ }^{10}$ found no relationship between HLA-DRB1*15:01 and the LL. However, the latter found correlations of the LL and brain volume with multiple SNPs (but they did not examine any SNP examined in the present study).

In a genetic study, the peculiarities of the population of interest can sometimes explain the differences in the results. We studied a Brazilian cohort, and the diversity of our findings could be related to this feature.

This study has some limitations. First, clinical and imaging data were not obtained over prolonged MS disease courses. We randomly selected a single time point representing each patient's illness, which was infrequently the time of the last MRI examination. This random selection was made to mitigate selection bias. Second, the analysis of the LL was done manually rather than automated an in recent publications. We chose the manual technique (old method) because it allows simultaneous evaluation of the brain in three different regions justacortical, periventricular and posterior fossa, optic nerve, and spinal cord. Automatic segmentation methods require separate analyses and have limitations in spliting the central nervous system. This limitation was mitigated by independent evaluation by two experienced observers blinded to patient clinical data. Imaging companies need to develop a reliable method to do this automatically.

In conclusion, in this analysis of MRI features in patients with MS, we found a significant association between a high LL and the presence of the HLA-DQA1*04:01 allele, which may represent a genetic susceptibility or predisposition. This specific allele has been associated with many different autoimmune diseases and MS.

Future structure-function studies are needed to uncover the specific mechanisms by which DQA1*04:01 or other haplotypes may cause these neuroradiological findings.

\section{SUPPLEMENTARY MATERIAL}

The following material is available online for this article: https://www.arquivosdeneuropsiquiatria.org/wp-content/ uploads/2021/11/OK-ANP_2020.0487-Supplementary-Files.pdf

\section{References}

1. International Multiple Sclerosis Genetics Consortium, Wellcome Trust Case Control Consortium, Sawcer S, Hellenthal G, Pirinen M, Spencer CCA, et al. International Multiple Sclerosis Genetics Consortium, Wellcome Trust Case Control Consortium, Genetic risk, and a primary role for cell-mediated immune mechanisms in multiple sclerosis. Nature. 2011 Aug;476(7359):214-9. https://doi.org/10.1038/nature10251 Moutsianas L, Jostins L, Beecham AH, Dilthey AT, Xifara DK, Ban M, et al. Class II HLA interactions modulate genetic risk for multiple sclerosis. Nat Genet. 2015 Oct;47(10):1107-13. https://doi. org/10.1038/ng.3395

3. Oksenberg JR, Barcellos LF, Cree BA, Baranzini SE, Bugawan TL, Khan $\mathrm{O}$, et al. Mapping multiple sclerosis susceptibility to the HLADR locus in African Americans. Am J Hum Genet. 2004 Jan;74(1):1607. https://doi.org/10.1086/380997
4. Dyment DA, Herrera BM, Cader MZ, Willer CJ, Lincoln MR, Sadovnick $A D$, et al. Complex interactions among MHC haplotypes in multiple sclerosis: susceptibility and resistance. Hum Mol Genet. 2005 Jul;14(14):2019-26. https://doi.org/10.1093/hmg/ddi206

5. Zhang Q, Lin CY, Dong Q, Wang J, Wang W. Relationship between HLA-DRB1 polymorphism and susceptibility or resistance to multiple sclerosis in Caucasians: a meta-analysis of non-family based studies. Autoimmun Rev. 2011 Jun;10(8):474-81. https://doi. org/10.1016/j.autrev.2011.03.003

6. Lincoln MR, Montpetit A, Cader MZ, Saarela J, Dyment DA, Tiislar M, et al. A predominant role for the HLA class II region in the association of the $\mathrm{MHC}$ region with multiple sclerosis. Nat Genet. 2005 Oct;37(10):1108-12. https://doi.org/10.1038/ng1647 
7. Masterman T, Ligers A, Olsson T, Andersson M, Olerup O, Hillert J. HLA-DR15, is associated with lower age at onset in multiple sclerosis. Ann Neurol. 2000 Aug;48(2):211-9.

8. Roxburgh RHSR, Seaman SR, Masterman T, HensiekAE, Sawcer SJ, Vukusic S, et al. Multiple Sclerosis Severity Score: using disability and disease duration to rate disease severity. Neurology. 2005 Apr;64(7):114451. https://doi.org/10.1212/01.WNL.0000156155.19270.F8

9. International Multiple Sclerosis Consortium. Multiple Sclerosis genomic map implicates peripheral immune cells and microglia in susceptibility. Science. 2019 Sep;365(6460):eaav7188. https://doi. org/10.1126/science.aav7188

10. Baranzini SE, Wang J, Gibson RA, Galwey N, Naegelin Y, Barkhof F, et al. Genome-wide association analysis of susceptibility and clinical phenotype in multiple sclerosis. Hum Mol Genet. 2009 Feb;18(4):767-78. https://doi.org/10.1093/hmg/ddn388

11. Pereira, VCSR, Fontes-Dantas FL, Paradela E, Malfetano FR, Scherpenhuijzen SSB, Mansur LF, et al. Polymorphisms in the CIITA -168A/G (rs3087456) and CIITA +1614G/C (rs4774) may influence severity in multiple sclerosis patients. Arq Neuro-Psiquiatr. 2019 Mar;77(3):166-73. https://doi.org/10.1590/0004-282X20190026

12. Thompson AJ, Banwell BL, Barkhof F, Carroll WM, Coetzee T, Comi $\mathrm{G}$, et al. Diagnosis of multiple sclerosis: 2017 revisions of the McDonald criteria. Lancet Neurol. 2018 Feb;17(2):162-73. https://doi. org/10.1016/S1474-4422(17)30470-2

13. Kurtzke JF. Rating neurologic impairment in multiple sclerosis: an expanded disability status scale (EDSS). Neurology. 1983 Nov;33(11):1444-52. https://doi.org/10.1212/wnl.33.11.1444

14. Gouraud PA, Sdika M, Khankhanian P, Henry RG, Beheshtian A, Matthews PM, et al. A genome-wide association study of brain lesion distribution in multiple sclerosis. Brain. 2013 Apr;136(Pt 4):1012-24. https://doi.org/10.1093/brain/aws363

15. Kalincik T, Guttmann CR, Krasensky J, Vaneckova M, Lelkova P, Tyblova M, et al. Multiple sclerosis susceptibility loci do not alter clinical and MRI outcomes in clinically isolated syndrome. Genes Immun. 2013 Jun;14(4):244-8. https://doi.org/10.1038/gene.2013.17

16. Alves-Leon SV, Papais-Alvarenga R, Magalhães M, Alvarenga M, Thuler LCS, Fernández y Fernandez O. Ethnicity-dependent association of HLA DRB1-DQA1-DQB1 alleles in Brazilian Multiple Sclerosis patients. Acta Neurol Scand. 2007 May;115(5):306-11. https://doi.org/10.1111/j.1600-0404.2006.00750.x

17. Paradela ER, Alves-Leon SV, Figueiredo ALS, Pereira VCRS, Malfetano F, Mansur LF, et al. The CIITA genetic polymorphism rs $4774{ }^{*} \mathrm{C}$ in combination with the HLA-DRB1*15:01 allele as a putative susceptibility factor to multiple sclerosis in Brazilian females. Arq Neuro-Psiquiatr. 2015 Apr;73(4):283-8. https://doi. org/10.1590/0004-282X20150012

18. Farina F, Picascia S, Pisapia L, Barba P, Vitale S, Franzese A, et al. HLA-DQA1, and HLA-DQB1 alleles conferring susceptibility to celiac disease and type 1 diabetes, are more expressed than nonpredisposing alleles and are coordinately regulated. Cells. 2019 Jul;8(7):751. https://doi.org/10.3390/cells8070751

19. Rajaei E, Jalali MT, ShahrabiS, Asnafi AA, Pezeshki SMS. HLAs in autoimmune diseases: dependable diagnostic biomarkers? Curr Rheumatol Rev. 2019;15(4):269-76. https://doi.org/10.2174/1573397 115666190115143226
20. LiC, Zhou Y, Xiang X, Zhou Y, He M. The relationship of HLADQ alleles with tuberculosis risk: a meta-analysis. Lung. 2015 Aug;193(4):521-30. https://doi.org/10.1007/s00408-015-9747-1

21. Lincoln MR, Ramagopalan SV, Chao MJ, Herrera BM, DeLuca GC, Orton SM, et al. Epistasis among HLA-DRB1, HLA-DQA1, and HLADQB1 loci determines multiple sclerosis susceptibility. PNAS. 2009 May;106 (18) 7542-7. https://doi.org/10.1073/pnas.0812664106

22. Marrosu MG, Murru MR, Costa G, R Murru, F Muntoni, F Cucca. DRB1-DQA1-DQB1 loci and multiple sclerosis predisposition in the Sardinian population. Hum Mol Genet. 1998 Aug;7(8):1235-7. https:// doi.org/10.1093/hmg/7.8.1235

23. Luckey D, Bastakoty D, Mangalam AK. Role of HLA Class II genes in susceptibility and resistance to multiple sclerosis: studies using HLA transgenic mice. J Autoimmun. 2011 Sep;37(2):122-8. https://doi. org/10.1016/j.jaut.2011.05.001

24. Zivadinov R, Uxa L, Zacchi T, Nasuelli D, Ukmar M, Furlan C, et al. HLA genotypes and disease severity assessed by magnetic resonance imaging findings in patients with multiple sclerosis. J Neurol. 2003 Sep;250(9):1099-106. https://doi.org/10.1007/s00415-003-0164-7

25. Zivadinov R, Uxa L, Bratina A, et al. HLA-DRB1 * 1501, -DQB1 * 0301, -DQB1 * 0302, -DQB1 * 0602, and -DQB1 * 0603 alleles are associated with more severe disease outcome on MRI in patients with multiple sclerosis. Int Rev Neurobiol. 2007;79:521-35. https:// doi.org/10.1016/S0074-7742(07)79023-2

26. Zivadinov R, Weinstock-Guttman B, Zorzon M, Uxa L, Serafin M, Bosco A, et al. Gene-environment interactions between HLA B7/A2, EBV antibodies are associated with MRI injury in multiple sclerosis. J Neuroimmunol. 2009 Apr;209(1-2):123-30. https://doi.org/10.1016/j. jneuroim.2009.01.023

27. Okuda DT, Srinivasan R, Oksenberg JR, Goodin DS, Baranzini SE, Beheshtian A, et al. Genotype-phenotype correlations in multiple sclerosis: HLA genes influence disease severity inferred by $1 \mathrm{HMR}$ spectroscopy and MRI measures. Brain. 2009 Jan;132(Pt 1):250-9. https://doi.org/10.1093/brain/awn301

28. Hooper-van Veen T, Berkhof J, Polman CH, Uitdehaag BMJ. Analysing the effect of candidate genes on complex traits: an application in multiple sclerosis. Immunogenetics. 2006 Jun;58(5-6):347-54. https://doi.org/10.1007/s00251-006-0116-3

29. Schreiber K, Oturai A, Ryder L, Madsen HO, Jørgensen OS, Svejgaard $A$, et al. Disease severity in Danish multiple sclerosis patients evaluated by MRI and three genetic markers (HLADRB1*1501, CCR5 deletion mutation, apolipoprotein E). Mult Scler. 2002 Aug;8(4):2958. https://doi.org/10.1191/1352458502ms816oa

30. Lysandropoulos AP, Mavroudakis N, Pandolfo M, El Hafsi K, van Hecke W, Maertens A, et al. HLA genotype as a marker of multiple sclerosis prognosis: a pilot study. J Neurol Sci. 2017 Apr;375:348354. https://doi.org/10.1016/j.jns.2017.02.019

31. Lysandropoulos AP, Perrotta G, Billiet T, Ribbens A, Du Pasquier R, Kreis CP, et al. Human leukocyte antigen genotype as a marker of multiple sclerosis prognosis. Can J Neurol Sci. 2020 Mar;47(2):18996. https://doi.org/10.1017/cjn.2019.329

32. Sombekke MH, Lukas C, Crusius JB, Tejedor D, Killestein J, Arteta D, et al. HLADRB1 * 1501 and spinal cord magnetic resonance imaging lesions in multiple sclerosis. Arch Neurol. 2009 Dec;66(12):1531-6. https://doi.org/10.1001/archneurol.2009.278 